\title{
Short- and medium-chain chlorinated paraffins in sediments from the Laizhou Bay area, North China: Implications for transportation from rivers to marine environment ${ }^{\text {is }}$
}

\author{
Xiaohui Pan ${ }^{a}$, Jianhui Tang ${ }^{\text {a, }}{ }^{*}$, Chongguo Tian ${ }^{\text {a }}$, Jun Li $^{\text {b }}$, Gan Zhang ${ }^{\text {b }}$ \\ ${ }^{a}$ Yantai Institute of Coastal Zone Research, Chinese Academy of Sciences, Yantai, 264003, China \\ b State Key Laboratory of Organic Geochemistry, Guangzhou Institute of Geochemistry, Chinese Academy of Sciences, Guangzhou, 510640, China
}

\section{A R T I C L E I N F O}

\section{Article history:}

Received 23 May 2018

Received in revised form

24 September 2018

Accepted 25 September 2018

Available online 29 September 2018

\begin{abstract}
A B S T R A C T
The concentrations of short- and medium-chain chlorinated paraffins (SCCPs and MCCPs) were measured for riverine and marine sediments from the Laizhou Bay area in order to investigate their spatial distributions, possible sources and transport behaviors. Concentrations of SCCPs and MCCPs in riverine sediments varied from 8.4 to $2000 \mathrm{ng} \mathrm{g}^{-1} \mathrm{dw}$ and from 1.8 to $3200 \mathrm{ng} \mathrm{g}^{-1} \mathrm{dw}_{\text {, respectively. }}$ Higher concentrations were found exclusively at industrial sites. Emissions from local factories were the main source of CPs in river sediments of this region. It was 5-22 ng g-1 dw and 6-63 ng g ${ }^{-1} \mathrm{dw}_{\text {with an }}$ average value of $11 \mathrm{ng} \mathrm{g}^{-1} \mathrm{dw}$ and $9 \mathrm{ng} \mathrm{g}^{-1} \mathrm{dw}$ for SCCPs and MCCPs in marine sediments of Laizhou Bay, respectively. In addition to riverine input, ship related emissions are suggested to be another important source of CPs in the Laizhou Bay. MCCPs/SCCPs values and compositional profiles of SCCPs were found to vary along with CP concentrations. A distinct shift to congener groups with shorter carbon chains and lower chlorination from emission sources to remote areas was noticed. The role of log octanol-water partition coefficient $\left(\log \mathrm{K}_{\mathrm{ow}}\right)$ values indicated decisive in their transportation from emission sources to remote areas in the Laizhou Bay area.
\end{abstract}

(c) 2018 Elsevier Ltd. All rights reserved.

\section{Introduction}

Chlorinated paraffins (CPs), are industrial product with the general formula $\mathrm{C}_{\mathrm{n}} \mathrm{H}_{2 \mathrm{n}+2-\mathrm{z}} \mathrm{Cl}_{\mathrm{z}}$, consisting of $10-30$ carbon atoms and chlorine content from $30 \%$ to $70 \%$ by mass. Three groups short chain (C10 - C13, SCCPs), medium-chain (C14 - C17, MCCPs), and long-chain (C18 - C30, LCCPs) are included according to the length of their carbon chain. CPs have been widely used in industries, such as high-temperature lubricants in metal-working machinery and flame-retardant plasticizers. Many other new applications are being developed and rapidly popularized, for example, as additives in adhesives, paints, rubber and sealants (Feo et al., 2009).

The release of CPs into the environment could occur during various processes, among which production and consumption for the PVC, flame retardant and metal cutting fluid industries are

\footnotetext{
This paper has been recommended for acceptance by Maria Cristina Fossi.

* Corresponding author.

E-mail address: jhtang@yic.ac.cn (J. Tang).
}

thought to be the major ones (Tomy et al., 1999; Wei et al., 2016). CPs are ubiquitous in the environment and they have high bioaccumulation and biomagnification potentials due to their high $\mathrm{K}_{\mathrm{ow}}$ values. SCCPs have shown carcinogenic potential in rats and chronic toxicity in aquatic and soil organisms (Bezchlebová et al., 2007; Geng et al., 2015; Warnasuriya et al., 2000). SCCPs were listed in Annex A to curtail its production and use worldwide by the Eighth Conference of the Parties of Stockholm Convention in 2017. In contrast, reports on eco-toxicity tests of MCCPs are very limited; however, they were reported to possibly be more bioaccumulative than SCCPs because of their reduced biotransformation resulting from the longer carbon chain lengths (Fisk et al., 2000). There is scientific concern that exposure to MCCPs may be associated with increased risk of kidney toxicity (Cherrie and Semple, 2010). Studies have revealed that MCCPs are also persistent in the environment and their concentration levels experienced an increase due to the regulation of SCCPs (Yuan et al., 2017).

China is the world's largest producer and consumer of CPs. The annual production volumes have increased rapidly to about $1,050,000$ ton in 2013 (UNEP/POPS/POPRC.12/11/Add.3, 2017). However, according to Wei et al. (2016), there are no restrictive 
regulations on the production and use of CPs in China to date. As a result, relatively high $\mathrm{CP}$ concentration levels were found ubiquitous in a variety of environmental matrices in China. Laizhou Bay is a typical estuary-bay ecosystem and one of the three main bays of the Bohai Sea. The Laizhou Bay area has experienced rapid urbanization and industrialization, which has led to excessive water contamination in the last few decades. Various industries, including petro-chemical, marine chemical, paper, textile, gold mining, and manufacturing, are located in this area. Several rivers flowing through cities and industrial districts are discharging into the bay (Zhang et al.; Pan et al., 2011a; Zhang et al.). Besides, Laizhou Bay is surrounded by Shandong Province, which is a major CP-product supplier and has been proven to emit the highest levels of SCCPs into the atmosphere in China from 2008 to 2012 (Jiang et al., 2017; Zhang et al., 2017).

Previous studies have suggested that river sediments are more or less contaminated by different organic pollutants (Zhang et al.; Pan et al., 2011a; Pan et al., 2011b; Zhang et al.; Zhao et al., 2013b; Zhong et al., 2011). Since there is a limited amount of existing data on CPs in the Laizhou Bay area, we collected sediment samples from the bay and 12 tributaries flowing into the bay. The sampling details are described in our previous studies (Pan et al., 2011a). The purpose of this work is to get an overview of the concentration levels and congener profiles in this area and discuss the possible transport pathways of CPs from emission sources to the marine environment. This article aims to offer a sight into the ecosystem risk evaluation of CPs and guide the further development of regulations for environmental control of CPs in the Laizhou Bay area.

\section{Materials and methods}

\subsection{Sample pretreatment}

The extraction and purification procedure of CPs in sediments was similar with that of polychlorinated naphthalenes (PCNs) and polybrominated diphenyl ethers (PBDEs) which was reported in our previous paper (Pan et al., 2011a; Pan et al., 2011b). Freezedried sediment samples (approximately $20-40 \mathrm{~g}$ of riverine samples and $80 \mathrm{~g}$ of marine samples) were spiked with $10 \mathrm{ng}$ surrogate standard $\left(\left[{ }^{13} \mathrm{C}_{10}\right]\right.$ trans-chlordane, purchased Cambridge Isotope Laboratories) and soxhlet extracted with $500 \mathrm{~mL}$ dichloromethane (DCM). Activated copper granules were added to the extraction flasks to remove elemental sulfur. The extract was then concentrated and cleaned up with a multilayer silica composite column consisted of $3 \mathrm{~cm}$ pre-rinsed silica gel ( $3 \%$ deactivated), $3 \mathrm{~cm}$ acid silica gel $(50 \%, \mathrm{w} / \mathrm{w})$ and $1 \mathrm{~cm}$ anhydrous sodium sulphate from bottom to top. The extract was eluted in sequence with $15 \mathrm{~mL}$ of hexane (F1) and $15 \mathrm{~mL}$ of DCM/HEX (1:1, v/v) (F2). Fraction F2 which contained $\mathrm{CPs}$ was reduced and spiked with internal standard (20 ng of $\left[{ }^{13} \mathrm{C}_{8}\right]$ mirex purchased from Ehrenstorfer $\mathrm{GmbH}$ ) before instrumental analysis.

\subsection{Instrumental analysis, quantification and quality assurance}

Instrumental analysis was performed by a high-resolution gas chromatograph coupled with electron capture negative ion-low resolution mass spectrometer (HRGC/ECNI-LRMS, Agilent, USA). The two most abundant isotopes of the $[\mathrm{M}-\mathrm{Cl}]^{-}$ions with $5-10$ chlorine atoms were monitored (Iozza et al., 2009; Reth and Oehme, 2004). In order to reduce interferences between SCCP and MCCP congener groups, all monitored ions were divided into two groups (Table S1). Each sample was subjected to analysis by two individual injections. For each injection, the corresponding SCCPs and MCCPs were simultaneously monitored. SCCP and MCCP congener groups were identified by comparing retention time and chromatographic peak shapes of monitored $[\mathrm{M}-\mathrm{Cl}]^{-}$ions. The quantification of CPs in sediment samples was based on the procedure described by Reth et al. (2005) to compensate the influence of chlorine contents on the total response factors between environmental samples and $\mathrm{CP}$ standards. Commercial references of SCCP/MCCP (C10-13, 51.5\%, 55.5\% and 63.0\% chlorine content; C14$17,42.0 \%, 52.0$ and $57.0 \%$ chlorine content) were mixed in different proportions to establish the calibration curves of total response factor (RF) versus $\mathrm{Cl}$ content for the quantitation purpose (Table S2). Good linear correlations were obtained as shown in Fig. S1. Chemical calculation using an algebraic equation group was conducted to reduce the interference from mass overlap between SCCPs and MCCPs (Zeng et al., 2011a). Congener group abundance profiles were established using the actual relative integrated signals, followed by chemical calculation to determine the relative concentrations of the molecular component in the commercial standards and environmental samples (Tomy et al., 1997; Zeng et al., 2011a).

\subsection{Quality assurance and quality control}

Every effort was made to reduce blank levels. Glassware and sodium sulphate were heated at $450^{\circ} \mathrm{C}$ for $12 \mathrm{~h}$ and solvent rinsed prior to use. Limits of detection (LOD) were defined as average method blank level plus three times the standard deviation, indicating that CPs were detectable in the blanks at concentrations relevant for real sample analysis. In this study, for each batch of 8 field samples one procedural blank and one sample duplicate was processed. LOD was calculated from the blank levels, and the obtained values were $38 \pm 2.8 \mathrm{ng} \mathrm{g}^{-1} \mathrm{dw}$ and $13 \pm 2.7 \mathrm{ng} \mathrm{g}^{-1} \mathrm{dw}$ for SCCPs and MCCPs, respectively. Average recoveries for the surrogate standard $\left[{ }^{13} \mathrm{C}_{10}\right]$ trans-chlordane were between 79 and $106 \%$. Duplicate samples reported relative standard deviation (RSDs) within $20 \%$ for all the target chemicals. All the samples were corrected by blanks but not by surrogate recoveries.

\section{Results and discussions}

The calculated chlorine content for SCCPs of all the samples for the calculation of total response factors fall well in the linear scope (Table S2 - S3). For MCCP calculation, only three samples went out of the linear scope. The nearest chlorine content within the scope were introduced for the three samples. $\mathrm{C} 15 \mathrm{Cl} 5, \mathrm{C} 16 \mathrm{Cl} 5$ and $\mathrm{C} 17 \mathrm{Cl} 5$ were not detected. SCCP concentrations at GLH2 is under LOD. There are some limitations of the method used in present study, such as that low chlorinated CPs ( $\mathrm{Cl} 1$ - C14) cannot be detected with the method in present study. Information on CPs only with 5-10 chlorine atoms was obtained, which may cause underestimation of the concentration levels. Besides, only total concentrations of SCCPs/MCCPs were obtained instead of that of individual congener group (Gao et al., 2016; Hilger et al., 2013). Therefore, comparisons of concentrations levels and congener group patterns in following sections were conducted with other studies using similar analytical method.

\subsection{Concentration levels of SCCPS and MCCPS}

The spatial distributions are shown in Fig. 1. It can be seen that CPs concentrations varied greatly in riverine sediments. SCCPs concentrations were in the range of $8.4-2000 \mathrm{ng} \mathrm{g}^{-1} \mathrm{dw}$ with a mean value of $160 \mathrm{ng} \mathrm{g}^{-1} \mathrm{dw}$. Over $75 \%$ of the riverine samples were below $50 \mathrm{ng} \mathrm{g}^{-1} \mathrm{dw}$. Samples ranging from 51 to $2000 \mathrm{ng} \mathrm{g}^{-1} \mathrm{dw}$ were found exclusively at industrial sites, especially near their local discharges. Site DH2 (2000 $\left.\mathrm{ng} \mathrm{g}^{-1} \mathrm{dw}\right), \mathrm{MH} 2\left(1200 \mathrm{ng} \mathrm{g}^{-1} \mathrm{dw}\right)$, YHH1 (510 $\mathrm{ng} \mathrm{g}^{-1} \mathrm{dw}$ ), and YKG (350 $\mathrm{ng} \mathrm{g}^{-1} \mathrm{dw}$ ) were sampled 


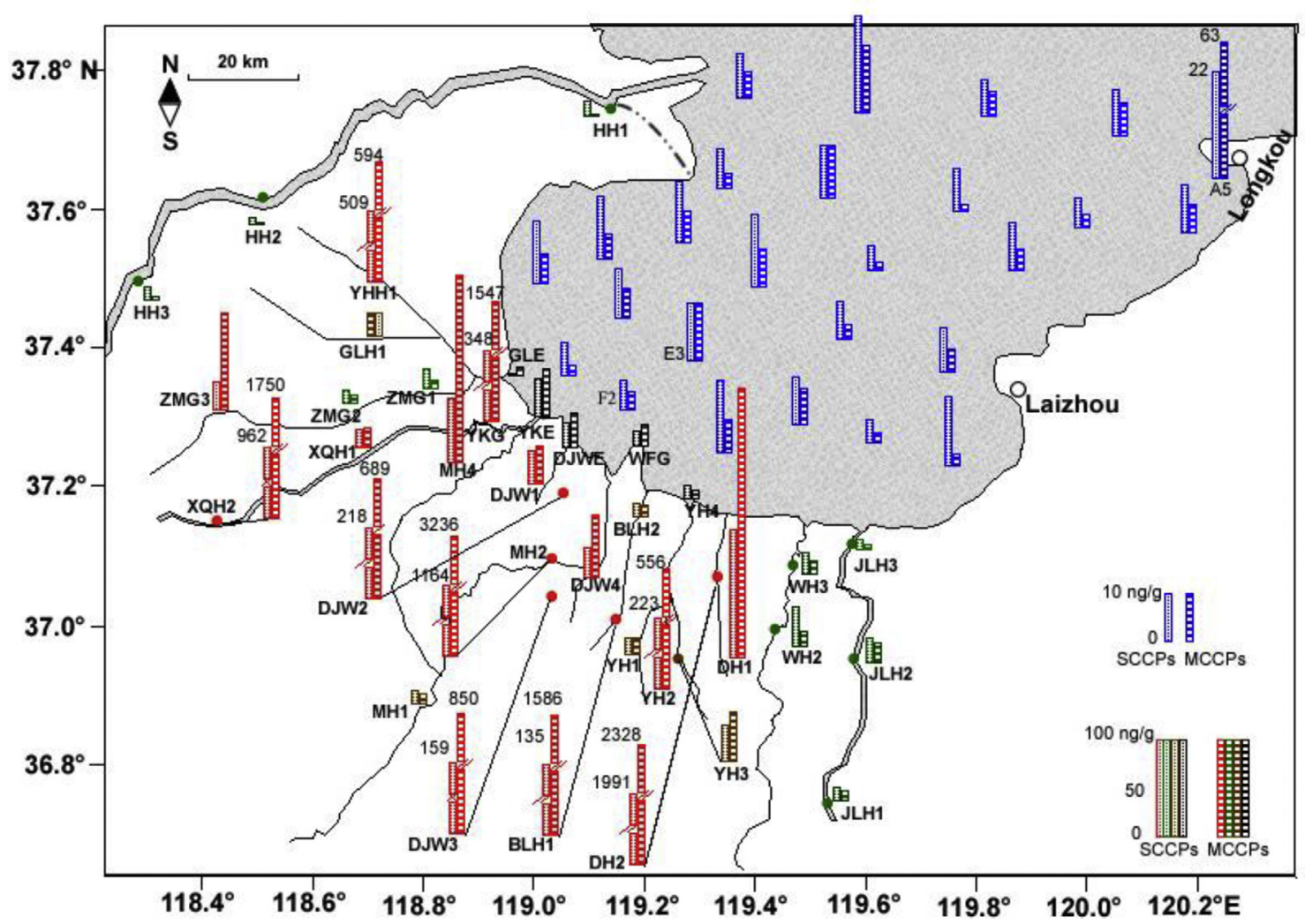

Fig. 1. Spatial distributions of SCCPs and MCCPs concentrations.

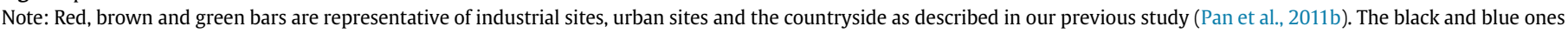
mean river estuaries and marine sites. (For interpretation of the references to colour in this figure legend, the reader is referred to the Web version of this article.)

from the lower reaches of the paper mill and textile industries, from around a chemical plant, from the Shengli Oil Field, and from within an industrial river port, respectively. These results are similar to those obtained in our previous study of Polychlorinated naphthalenes (PCNs) and Polybrominated diphenyl ethers (PBDEs) in this region (Pan et al., 2011a; Pan et al., 2011b). Thus, it can be seen that emissions from local factories were likely the main source of SCCPs in river sediments of this region. The lowest concentrations at site HH2, GLE, and JLH3 were found on a vast saline and alkaline land relatively far from human activities. According to the general sampling groups (Pan et al., 2011b), the mean concentrations decreased by one magnitude in the following order: $320 \mathrm{ng} \mathrm{g}^{-1} \mathrm{dw}$ (industrial group), $22 \mathrm{ng} \mathrm{g}^{-1} \mathrm{dw}$ (urban group with less industries), $6.5 \mathrm{ng} \mathrm{g}^{-1} \mathrm{dw}$ (the countryside group). We suggest that the distributions of CP concentrations are mainly controlled by the proximity of the sampling sites to industrial and/or local discharges.

The spatial distributions of MCCPs in rivers were similar to that of SCCPs. This can also be illustrated by the significant correlation between SCCP and MCCP concentrations $(R=0.809, p<0.01)$, which are in the range of $1.8-3200 \mathrm{ng} \mathrm{g}^{-1} \mathrm{dw}$, with an average value of $360 \mathrm{ng} \mathrm{g}^{-1} \mathrm{dw}$. In over $70 \%$ of the riverine samples, MCCP concentrations were below $100 \mathrm{ng} \mathrm{g}^{-1} \mathrm{dw}$. A few samples with higher concentrations were found in the industrial area.

For marine sediments, there is a sharp decrease up to $1-2$ orders of magnitude from riverine sediments located in the most industrialized areas. They were $5.1-22 \mathrm{ng} \mathrm{g}^{-1} \mathrm{dw}$ and $2.2-63 \mathrm{ng} \mathrm{g}^{-1} \mathrm{dw}$ with an average value of $11 \mathrm{ng} \mathrm{g}^{-1} \mathrm{dw}$ and $9 \mathrm{ng} \mathrm{g}^{-1} \mathrm{dw}$ for SCCPs and MCCPs respectively. The highest CPs concentrations occurred at site A5 near Longkou port in the east coast of Laizhou Bay and it was with very low TOC value. An ENVISAT ASAR image based on wide swath SAR was used to identify possible ship-related sources (Fig. 2). This image was scanned at 10:10:45 on 04-23-2011 with a spatial resolution of $150 \mathrm{~m} \times 150 \mathrm{~m}$. A dense concentration of white light spots in Longkou port anchorage indicated a large number of moored ships. Thus discharge from ports or ship-related activities is probably another important source of CPs in Laizhou bay. The image also reveals that there are many moored ships anchoring in Weifang port, where site E3 (SCCP: $12 \mathrm{ng} \mathrm{g}^{-1} \mathrm{dw}$; MCCP:12 $\mathrm{ng} \mathrm{g}^{-1}$ $\mathrm{dw}$ ) was located, with the concentration was two and three times higher than F2 (SCCP: $6.6 \mathrm{ng} \mathrm{g}^{-1} \mathrm{dw}$; MCCP:3.8 $\mathrm{ng} \mathrm{g}^{-1} \mathrm{dw}$ ). The ship-related activities discharge might also make contributions. The relatively higher concentrations in the central area from the south coast instead of a seaward decrease trend, such as site A2, A3, B2 and D3, is similar with distributions of PCNs and PBDEs in our previous studies (Pan et al., 2011a; Pan et al., 2011b), which could be attributed to a comprehensive influence by sedimentation type and hydrodynamic forces apart from different source input.

Although great progress has been made in recent years, there is still a lack of environmental data regarding CPs especially MCCPs in sediments among different countries/regions worldwide. The concentrations in sediments worldwide were summarized in Table 1. Compared with sediments from freshwaters reported in other countries, SCCP concentrations in rivers around the Laizhou Bay area are much higher, such as Czech rivers of the Czech Republic (nd-347 $\mathrm{ng} \mathrm{g}^{-1} \mathrm{dw}$ ), rivers in Japan including Arakawa, Tamagawa, and Yodogawa River (4.9-484.4 $\mathrm{ng} \mathrm{g}^{-1} \mathrm{dw}$ ), and lakes in Canada (Iino et al., 2005; Ismail et al., 2009; Pribylová et al., 2006; Stejnarová et al., 2005). Compared with those from industrial areas in more developed regions, such as sediments in the marine coast near Barcelona (SCCPs: $840-2740 \mathrm{ng} \mathrm{g}^{-1} \mathrm{dw}$ ), Besos 


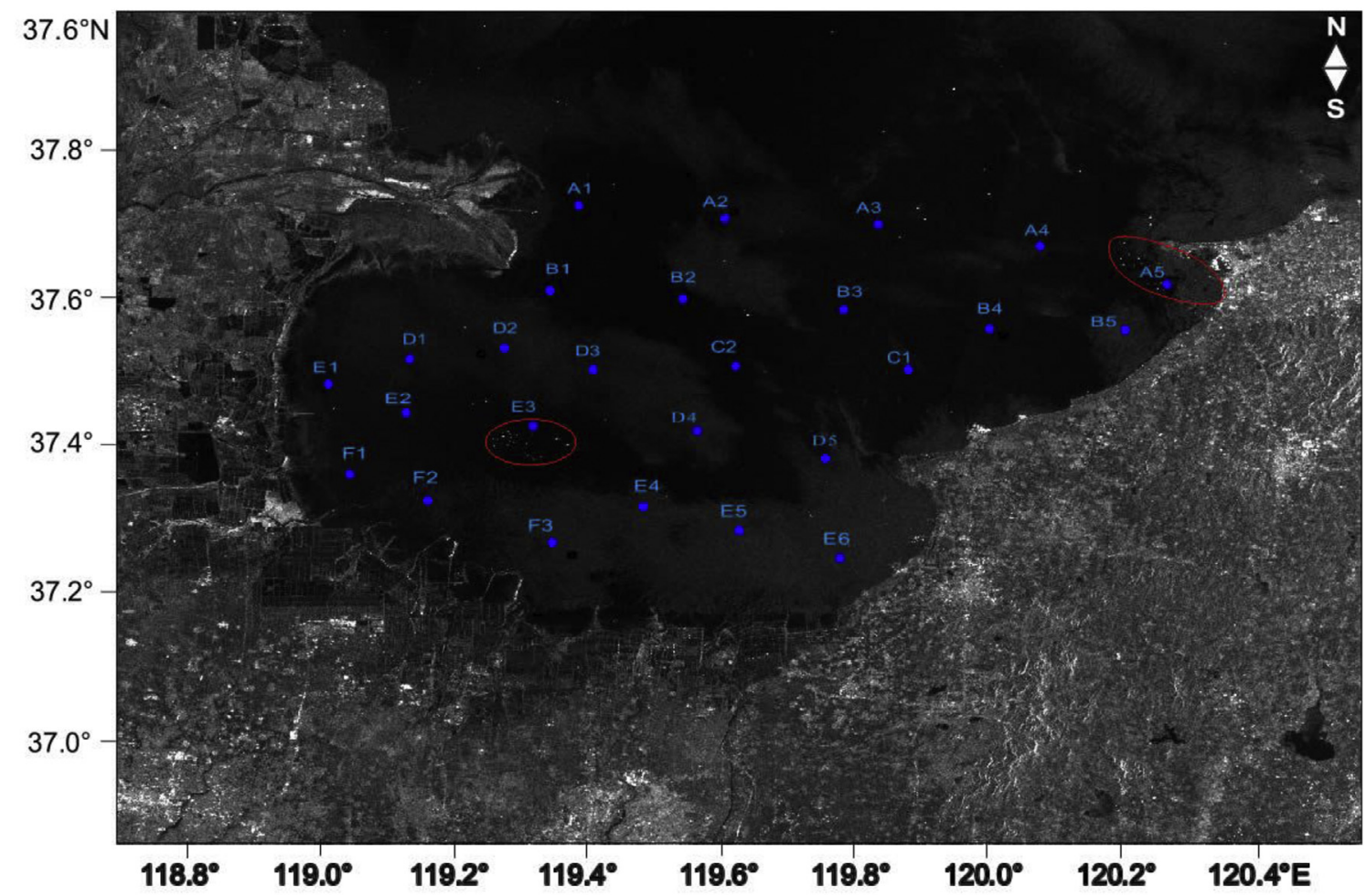

Fig. 2. Geographic locations of marine sediments and mooring ships in Laizhou Bay. Note: It is ENVISAT ASAR images data and the white lightspots are representative of ships.

River in Spain (SCCPs: 250-3040 $\mathrm{ng} \mathrm{g}^{-1} \mathrm{dw}$ ), and the Pearl River Delta in south China (SCCPs: $320-6600 \mathrm{ng} \mathrm{g}^{-1} \mathrm{dw}$; MCCPs: $880-38000 \mathrm{ng} \mathrm{g}^{-1} \mathrm{dw}$ ), and those from aquatic Ecosystem receiving effluents from a Sewage Treatment Plant in Beijing of China (1100-8700 $\mathrm{ng} \mathrm{g}^{-1} \mathrm{dw}$ ), CP levels in Laizhou Bay area are relatively lower (Castells et al., 2008; Castells et al., 2004; Chen et al., 2011; Zeng et al., 2011b). SCCPs in marine sediments of Laizhou Bay area are slightly lower than those found in Bohai and Yellow seas (14.5-85.2 $\mathrm{ng} \mathrm{g}^{-1} \mathrm{dw}$ ), Liaodong Bay (65-541 $\mathrm{ng} \mathrm{g}^{-1}$ $\mathrm{dw})$, Liaohe River Basin (39.8-480.3 $\left.\mathrm{ng} \mathrm{g}^{-1} \mathrm{dw}\right)$, East China Sea (5.8-64.8 $\left.\mathrm{ng} \mathrm{g}^{-1} \mathrm{dw}\right)$, and Hongkong marine coast (<LOD $75.9 \mathrm{ng} \mathrm{g}^{-1} \mathrm{dw}$ ) (Gao et al., 2012; Ma et al., 2014b; Zeng et al., 2013; Zeng et al., 2017; Zeng et al., 2012). This slight difference on the same order of magnitude does not rule out the cause by the drawbacks of GC/ECNI-LRMS used in CP detection. Both SCCP and MCCP concentrations in marine sediments of Laizhou Bay area are similar with those found in North/Baltic Sea (SCCPs: 8-63 $\mathrm{ng} \mathrm{g}^{-1}$ dw; MCCPs: 22-140 ng g $^{-1} \mathrm{dw}$ ) (Huttig and Oehme, 2005). However, with the rapid development of $\mathrm{CP}$ production and usage in the last decade in Shandong Province (Jiang et al., 2017), CP concentrations in the Laizhou Bay area might undergo a big increase, which needs further attention and study.

\subsection{Correlations among CPs and TOC}

TOC has been considered a key factor influencing the accumulation of SCCPs in the sediment. In present study, Pearson's correlation analysis was conducted between TOC and CP concentrations. Riverine and marine sediments were implemented respectively due to their huge concentration span and different sources. No significant correlations were observed between $\sum$ SCCPs/ $\sum$ MCCPs and TOC in riverine sediments, which confirmed that local industrial emissions contributed mostly to the distributions of CPs in this area and this is consistent with that in the Liaohe River Basin (Gao et al., 2012). In marine sediments, significant correlations between $\sum$ SCCPs and TOC were reported in a few studies (Chen et al., 2011; Zeng et al., 2013; Zeng et al., 2012). In present study however, there was no significant correlations between $\sum$ SCCPs and TOC whereas $\sum$ MCCPs and TOC were significantly positively correlated $(R=0.633, p<0.01)$. This is very interesting and could be concerned with possibly different sources in marine environment. In riverine sediments, local industrial emissions covered up the impact of TOC and other possible sources. In marine sediments however, CPs may come from a comprehensive contribution of riverine/coastal input, atmospheric dry/wet deposition and other sources such as discharge from ship-related activities. Due to the different physical-chemical properties between SCCPs and MCCPs, the contributions of different sources varied and the transport abilities and/or pathways were also probably different. The strong correlation between MCCPs and TOC in marine sediments of Laizhou Bay indicated the key role of TOC on the distribution of MCCPs in the sediments.

\subsection{Ratios of MCCPs/SCCPs and compositional profiles}

In this study, MCCPs/SCCPs ratios were found to decrease with CP concentrations. $r_{1}$ was defined as $r_{1}=$ MCCPs/SCCPs -1 to give an intuitionistic description as shown in Fig. 3. The highest M/S values occurred at sites with significant high CPs concentrations sampled in industrial areas, varying from 1.1 to 5.6 with a mean value of 2.3. Lower $\mathrm{M} / \mathrm{S}$ values were found in urban areas with less industry. They were fluctuating narrowly at 1.0 with the values of $0.97 \pm 0.23$. For samples collected from the countryside, including WH sites, $\mathrm{HH}$ sites and JLH sites, M/S values varied between 0.14 and 0.86 , with an average value of 0.49 . In marine sediments, $\mathrm{M} / \mathrm{S}$ values varied between 0.18 and 1.0 in 28 out of 30 samples, with a 
Table 1

Comparison of worldwide concentrations of SCCPs and MCCPs (ng g-1, d.w.) in river and marine sediment.

\begin{tabular}{|c|c|c|c|c|c|c|}
\hline \multirow[t]{2}{*}{ Location/country } & \multirow[t]{2}{*}{ Sample type } & \multirow[t]{2}{*}{$\begin{array}{l}\text { Sampling } \\
\text { year }\end{array}$} & \multicolumn{2}{|c|}{$\begin{array}{l}\text { Concentration (ng } \\
\text { g-1 d.w.) }\end{array}$} & \multirow[t]{2}{*}{$\begin{array}{l}\text { Method of } \\
\text { Analysis }\end{array}$} & \multirow[t]{2}{*}{ Reference } \\
\hline & & & SCCPs & MCCPs & & \\
\hline $\begin{array}{l}\text { Rivers (Labe, Bilina, Ohre, Vltava, Jihlava, Dyje, Svitava, Morava, Becva, Mala Becva, } \\
\text { and Drevnice), Czech Republic }\end{array}$ & River sediment & $\begin{array}{l}2003 \\
-2004\end{array}$ & $\begin{array}{l}\text { LOD - } \\
347\end{array}$ & $\begin{array}{l}<\text { LOD - } \\
5574\end{array}$ & $\begin{array}{l}\text { GC/ECNI- } \\
\text { LRMS }\end{array}$ & $\begin{array}{l}\text { (Pribylová et al., } \\
\text { 2006) }\end{array}$ \\
\hline The North and Baltic Seas & Marine sediment & $\begin{array}{l}2003 \\
-2004\end{array}$ & $8-63$ & $22-149$ & $\begin{array}{l}\text { GC/ECNI } \\
\text {-LRMS }\end{array}$ & $\begin{array}{l}\text { (Huttig and } \\
\text { Oehme, 2006) }\end{array}$ \\
\hline Industrial area near of Barcelona, Spain & River sediment & NR & $\begin{array}{l}250 \\
-3260\end{array}$ & NA & $\begin{array}{l}\text { GC/ECNI- } \\
\text { LRMS }\end{array}$ & $\begin{array}{l}\text { (Castells et al., } \\
\text { 2004) }\end{array}$ \\
\hline Coastal area of Barcelona, Spain & Marine sediment & 2003 & $\begin{array}{l}840 \\
-2740\end{array}$ & NA & $\begin{array}{l}\text { GC/ECNI- } \\
\text { LRMS }\end{array}$ & $\begin{array}{l}\text { (Castells et al., } \\
\text { 2008) }\end{array}$ \\
\hline Bohai and Yellow Seas, China & Marine sediment & 2012 & $\begin{array}{l}14.5 \\
-85.2\end{array}$ & NA & $\begin{array}{l}\text { GC/ECNI- } \\
\text { LRMS }\end{array}$ & (Zeng et al., 2013) \\
\hline Bohai Sea Coast, China & Marine sediment & 2010 & $\begin{array}{l}97.4 \\
-1756.7\end{array}$ & NA & $\begin{array}{l}\text { GC/ECNI- } \\
\text { LRMS }\end{array}$ & (Ma et al., 2014a) \\
\hline Liaodong Bay, China & Marine sediment & NR & $65-541$ & NA & $\begin{array}{l}\text { GC/ECNI- } \\
\text { LRMS }\end{array}$ & (Ma et al., 2014a) \\
\hline Liaohe River Basin, China & $\begin{array}{l}\text { River/estuary } \\
\text { sediment }\end{array}$ & 2010 & $\begin{array}{l}39.8 \\
-480.3\end{array}$ & NA & $\begin{array}{l}\text { GC/ECNI- } \\
\text { LRMS }\end{array}$ & (Gao et al., 2012) \\
\hline East China Sea, China & Marine sediment & 2011 & $5.8-64.8$ & NA & $\begin{array}{l}\text { GC/ECNI- } \\
\text { LRMS }\end{array}$ & (Zeng et al., 2012) \\
\hline Pearl River Delta, China & $\begin{array}{l}\text { River/estuary } \\
\text { sediment }\end{array}$ & $\begin{array}{l}2009 \\
-2010\end{array}$ & $\begin{array}{l}320 \\
-6600\end{array}$ & $\begin{array}{l}880 \\
-38000\end{array}$ & $\begin{array}{l}\text { GC/ECNI- } \\
\text { LRMS }\end{array}$ & (Chen et al., 2011) \\
\hline Pearl River Delta, Coast of Shenzhen, China & $\begin{array}{l}\text { River/coastal } \\
\text { sediment }\end{array}$ & 2013 & $\begin{array}{l}14.7 \\
-1540\end{array}$ & $\begin{array}{l}10.9 \\
-6650\end{array}$ & $\begin{array}{l}\text { GC/ECNI- } \\
\text { LRMS }\end{array}$ & (Zeng et al., 2017) \\
\hline Hong Kong, China & Marine sediment & 2013 & $\begin{array}{l}<\text { LOD - } \\
75.9\end{array}$ & $\begin{array}{l}<\text { LOD } \\
-286\end{array}$ & $\begin{array}{l}\text { GC/ECNI- } \\
\text { LRMS }\end{array}$ & (Zeng et al., 2017) \\
\hline Arakawa river, Tamagawa river and Yodogawa river, Japan & River sediment & 2003 & $\begin{array}{l}4.9 \\
-484.4\end{array}$ & NA & $\begin{array}{l}\text { GC/ECNI- } \\
\text { HRMS }\end{array}$ & (Iino et al., 2005) \\
\hline Tokyo Bay, Japan & Marine sediment & 2013 & $\begin{array}{l}15.3 \\
-25.4\end{array}$ & $3.2-37.9$ & $\begin{array}{l}\text { GC/ECNI- } \\
\text { LRMS }\end{array}$ & (Zeng et al., 2017) \\
\hline Laizhou Bay, China & Marine sediment & 2009 & $5-22$ & $6-63$ & $\begin{array}{l}\text { GC/ECNI- } \\
\text { LRMS }\end{array}$ & this study \\
\hline Rivers around Laizhou Bay, China & River sediment & 2009 & $\begin{array}{l}8.4 \\
-2000\end{array}$ & $\begin{array}{l}1.8 \\
-3200\end{array}$ & $\begin{array}{l}\text { GC/ECNI- } \\
\text { LRMS }\end{array}$ & this study \\
\hline
\end{tabular}

NR: not reported; NA: not analyzed; < LOD: not detected or below detection of limitation.

mean value of 0.54, with two exceptions at site A5 (2.8) and site E3 (1.1). On the whole $r_{1}$ values in surface sediments followed the order of industrial area sediment $>$ urban sediment $>$ countryside sediment $>$ marine sediment. The relationship between $\mathrm{CP}$ concentrations and $\mathrm{M} / \mathrm{S}$ values was firstly reported by Chen et al. (2011); they found M/S ratios were well correlated with SCCP concentrations and could be used as an indicator to determine whether there are direct emission sources of CPs in a given region in the Pearl River Delta (PRD). In the present work, the values of M/ $S$ ratios directly reflected the influence of emission sources on sampling sites. They also illustrated the replacement of MCCP products by SCCPs in industries accompanied with the regulation of SCCP commercials, which confirmed environmental concern and the need for chemical management with regards to MCCPs (Wang et al., 2017). For site A5, the strong influence of Longkou port activities could contribute to its exceptional high $\mathrm{M} / \mathrm{S}$ value as well as high CP concentration. Compared to Longkou Port, Weifang harbor anchorage, located near site E3, is an ideal mooring basin for fishing boats, cargo ships, and container ships during poor weather conditions or while waiting for loading and unloading of goods. Thus, the $\mathrm{CP}$ concentrations and M/S values at E3 may be affected by direct emissions from ship-related activities.

The compositional contributions of individual carbon chain groups to $\Sigma$ SCCP varied among the different sampling sites in riverine sediments (Fig. 4). Generally, three different categories were observed. One was predominant, with the longest carbon chain group C13 homologue congener groups, as shown in Fig. 4a; most of the industrial samples with higher $\mathrm{CP}$ concentrations were in this category. In contrast, in the most remote areas such as HH1, $\mathrm{HH} 2$, and $\mathrm{HH} 3$, with the lowest CPs concentrations, shorter carbon chain groups (C10 and C11) were more abundant than C12 and C13 homologues, as shown in Fig. 4c. For other sediments, such as a few urban sites, river estuaries flowing through industrial areas, and some countryside sites near villages, no evidently dominant homologues were found and each individual group made similar contributions, as shown in Fig. $4 \mathrm{~b}$. The $6 \mathrm{Cl}$ to $8 \mathrm{Cl}$ congener groups were the dominant components in each carbon chain group (Fig. 4). Higher chlorinated congener groups $(7 \mathrm{Cl}$ and $8 \mathrm{Cl}$ ) were found to be more abundant in areas with higher SCCP concentrations, while the abundances of lower-chlorinated congener groups were elevated in the countryside and in the offshore sites.

The congener group patterns in the industrial category (Fig. 4a) highly resembled that in PRD and Shenzhen coastal sediments (Zeng et al., 2017). Chen et al. (2011) elaborated the compositional profiles in different areas of PRD. In comparison, the industrial category of present study differed from the highly industrialized areas in PRD and e-waste ponds, while the less industrialized category (Fig. 4b) resembled each other, and the remote group distant from industries (Fig. 4c) were similar with that in Pearl River Estuary (PRE).

In marine sediments, compositional profiles were consistent with each other, presenting small variations (except A5). C10 and C11 homologue were the most predominant carbon chain group, accounting for $33.2 \pm 8.5 \%$ and $31.3 \pm 2.1 \%$ to $\Sigma$ SCCPs respectively, followed by $\mathrm{C} 12$ at $18.9 \pm 3.0 \%$, and $\mathrm{C} 13$ homologue at $17.5 \pm 4.6 \%$. Contributions from C10 homologue were remarkably lower compared to Bohai Sea, Yellow Sea, East China Sea and Hongkong coastal zones (Zeng et al., 2013; Zeng et al., 2017; Zeng et al., 2012). But it was similar with Liaodong Bay and Tokyo Bay (Ma et al., 2014b; Zeng et al., 2017). Based on the chlorine groups, Cl6 - C17 


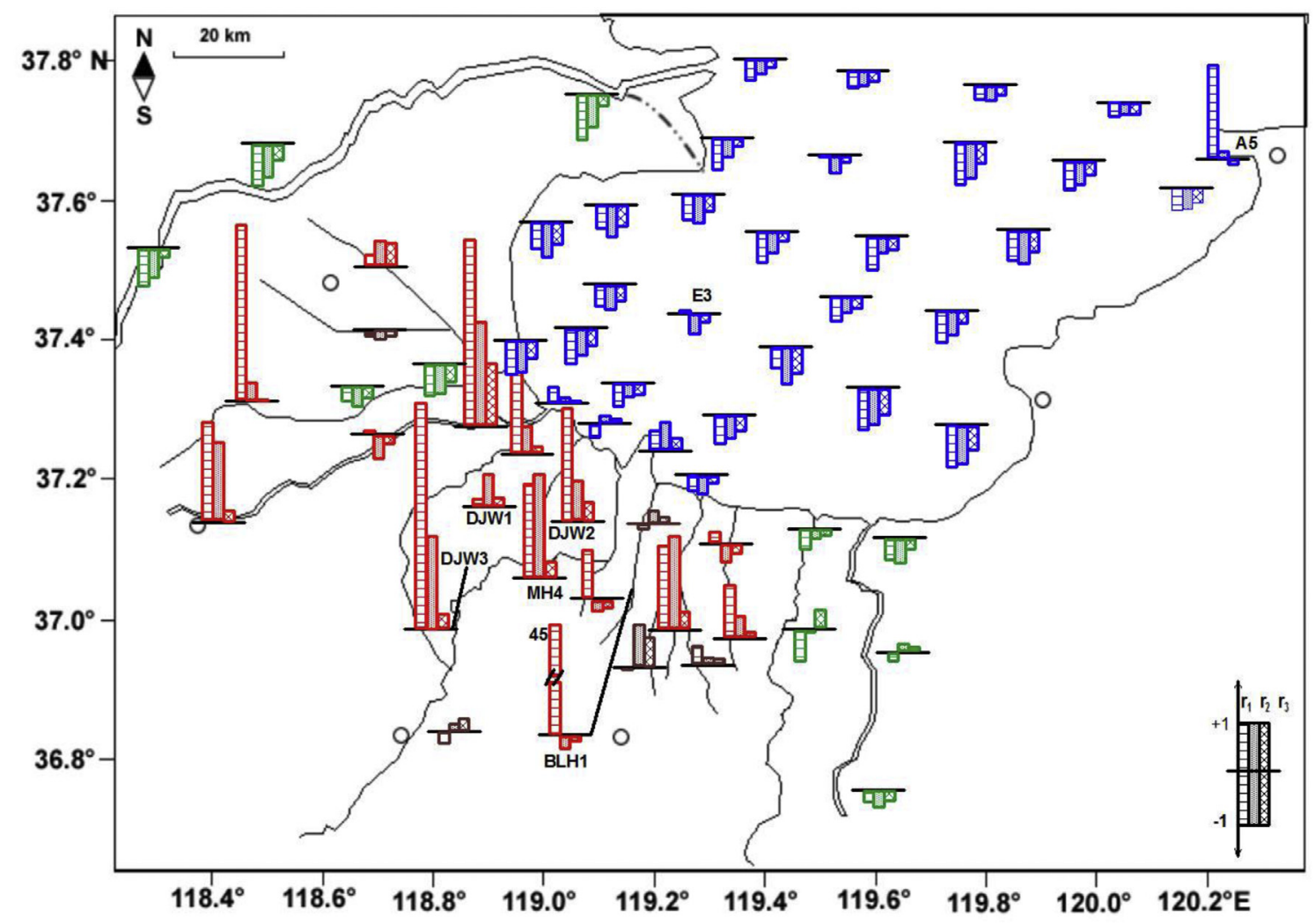

Fig. 3. Spatial distributions of $r_{1}, r_{2}$ and $r_{3}$ ratios concerning compositional profiles of CPs in sediments of the Laizhou Bay arear ${ }_{1}=$ Con.[MCCPs]/Con.[SCCPs] - 1 $\mathrm{r}_{2}=(\Sigma \mathrm{C} 12+\Sigma \mathrm{C} 13) /(\Sigma \mathrm{C} 10+\Sigma \mathrm{C} 11)-1$

$\mathrm{r}_{3}=(\Sigma 7 \mathrm{Cl}+\Sigma 8 \mathrm{Cl})_{\mathrm{SCCPs}} /(\Sigma 6 \mathrm{Cl}+\Sigma 7 \mathrm{Cl})_{\mathrm{SCCPs}}-1$.
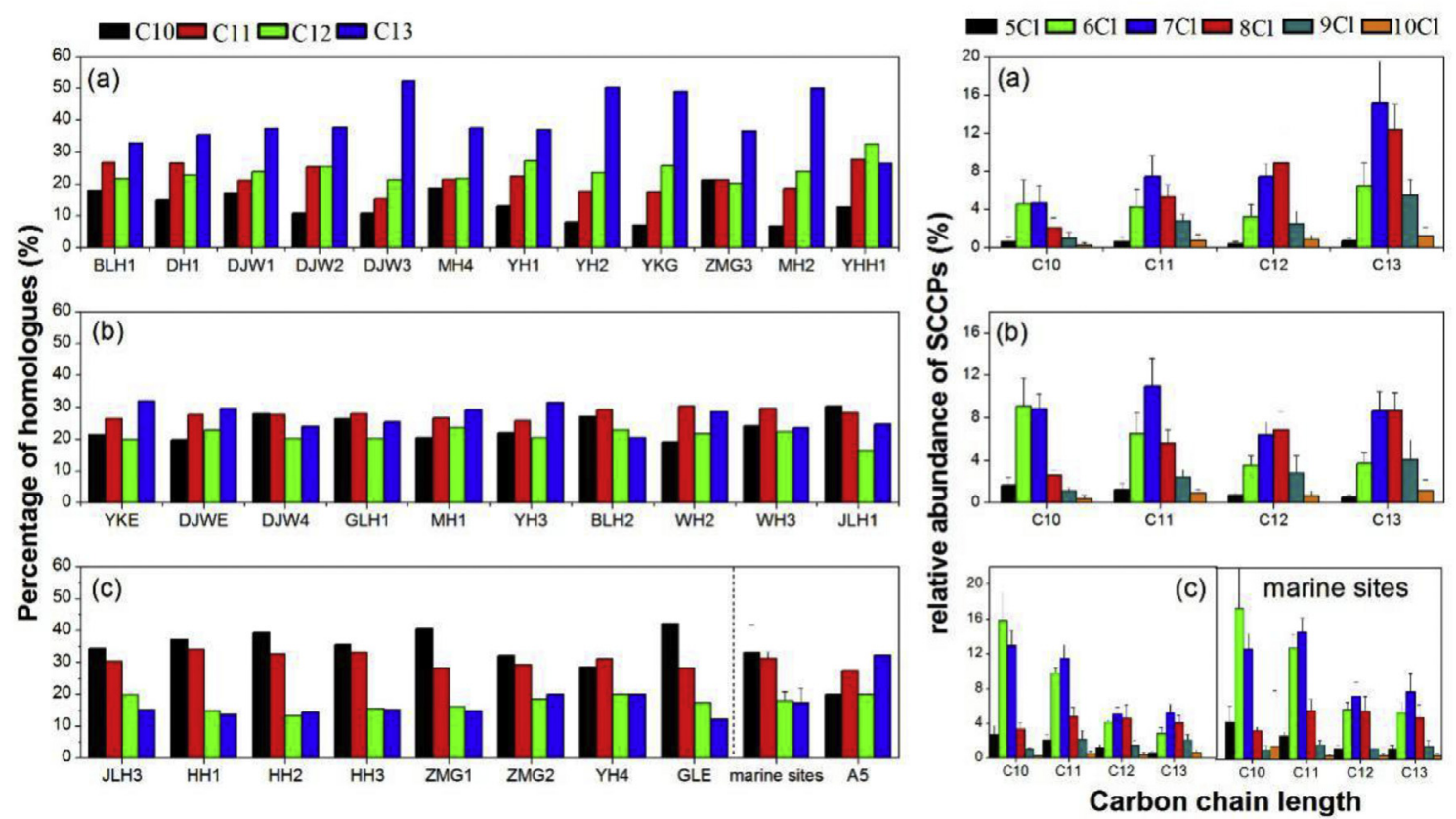

Fig. 4. Compositional profiles of SCCPs in sediments of the Laizhou Bay area

were the predominant congener groups, accounting for $34.0 \pm 4.5 \%$ and $34.9 \pm 3.5 \%$ to $\Sigma$ SCCPs respectively, followed by $\mathrm{Cl} 8$ group at $16.0 \pm 3.5 \%$, and they cumulatively accounted for $69.5 \pm 4.1 \%$. It is consistent with that found in Bohai Sea, Yellow Sea and East China
Sea. But compared with Liaodong Bay, Tokyo Bay and Hongkong coastal zones, congener groups with 5 chlorine atoms were obviously lower.

For MCCPs, their compositional profiles varied within a small 
scale both in riverine and marine sediments. They were consistently predominant by $6 \mathrm{Cl}$ to $8 \mathrm{Cl}$ chlorinated congener groups and the $\mathrm{C} 14$ homologue group. On average, the relative mass abundance was $61.6 \pm 11.1 \%, 20.3 \pm 4.4 \%, 11.1 \pm 4.7 \%$, and $7.0 \pm 3.3 \%$ in riverine sediments and $69.6 \pm 4.5 \%, 17.5 \pm 1.9 \%, 8.1 \pm 2.1 \%$, and $4.9 \pm 1.5 \%$ in marine sediments for C14, C15, C16, and C17 groups respectively. Similar to SCCP congener group profiles, the lightest group - C14 homologue group were significantly higher in marine than riverine sediments. The congener group profiles of MCCPs were similar to that reported in other studies, except for that the abundance proportion of C14 homologue was at the highest level reported up to now (Chen et al., 2011; Iozza et al., 2008; Zeng et al., 2017).

\subsection{Implications for transport}

A correlation analysis was performed between In (SCCPs) concentrations in riverine sediments and the abundance ratio of congener groups with different carbon atoms (Fig. 5). Significant correlations were found. While Short carbon chain (C10, C11) congener groups decreased with the increase of SCCP concentrations (C10: $R=-0.657, p<0.01 ; \mathrm{C} 11: R=-0.399, p<0.05), \mathrm{C} 12$ and C13 congener groups increased significantly (C12: $R=0.541$, $p<0.01 ; \mathrm{C} 13: R=0.548, p<0.01$ ), especially for the shortest (C10) and the longest chain (C13) group. The parameter $r_{2}$ was defined as $r^{2}=(\Sigma \mathrm{C} 12+\Sigma \mathrm{C} 13) /(\Sigma \mathrm{C} 10+\Sigma \mathrm{C} 11)-1$ to visually simplify the profile variations, as shown in Fig. 3. It can be seen that longer carbon chain groups (C12 and C13) decreased and shorter ones (C10 and C11) elevated from emission sources to less-industrialized areas with lower SCCP concentrations. The parameter $r_{3}$ was defined as $r_{3}=(\Sigma 7 \mathrm{Cl}+\Sigma 8 \mathrm{Cl}) /(\Sigma 6 \mathrm{Cl}+\Sigma 7 \mathrm{Cl})-1$ and it is consistent with $r_{2}$ distributions; there is also a shift from higher chlorinated congener groups near the emission sites to those with lower chlorination in remote areas and marine sediments (Fig. 3).

The fractionation of different $\mathrm{CP}$ components during the transportation from emission sources to remote areas is suggested from the discussion above. This is in agreement with a few other studies (Chen et al., 2011; Ma et al., 2014b; Zeng et al., 2012; Zhao et al., 2013a). The environmental behavior of organic pollutants is complicated and influenced by multiple factors. The log octanolwater partition coefficient $\left(\log \mathrm{K}_{\mathrm{ow}}\right)$ has been considered a key parameter for the measurement of organic pollutants in environmental fate modeling since it can be effectively correlated with water solubility and bioconcentration factors. A few studies reported the relationships between $K_{\text {ow }}$ values and the number of chlorine and carbon atoms, and/or their total numbers (Bettina et al., 2011; Drouillard et al., 1998; Mackay et al., 1993; Sijm and Sinnige, 1995). Hilger et al. (2013) probed the effects of chain length, chlorination degree, and chlorine substitution pattern on $\log \mathrm{K}_{\mathrm{ow}}$ values. The author found that while $\log \mathrm{K}_{\mathrm{ow}}$ values increased almost linearly with increasing carbon atoms in the
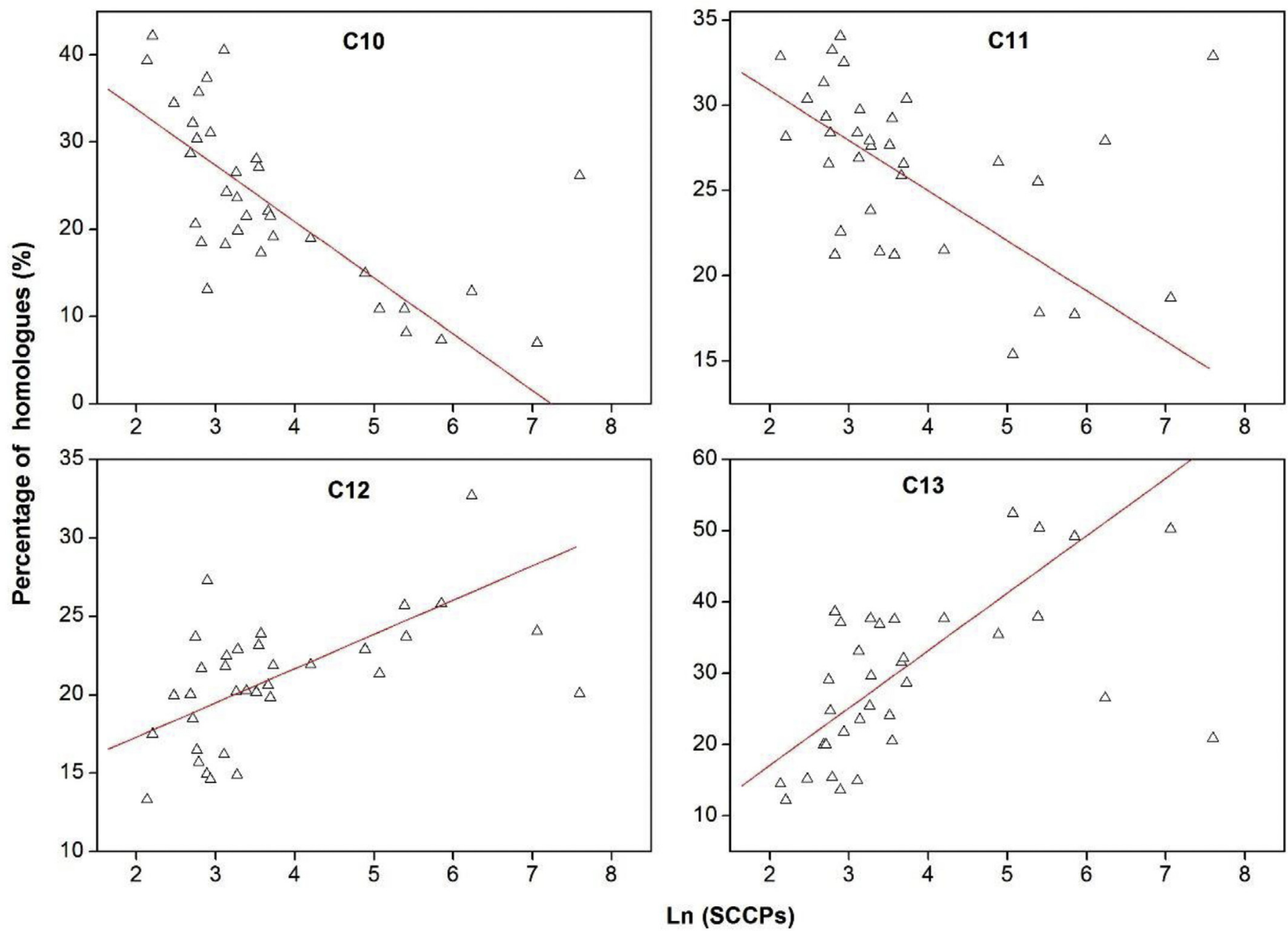

Fig. 5. Correlations between SCCPs concentrations in riverine sediments and abundance ratio of homologues. 
Table 2

Pearson correlation coefficients (R values) between ln (SCCPs) concentrations in riverine sediments and relative abundance ratio of congener groups.

\begin{tabular}{|c|c|c|c|c|c|c|c|c|}
\hline & 10,5 & 10,6 & 11,5 & 11,6 & 10,7 & 11,7 & 12,5 & 12,6 \\
\hline Log Kow & 4.98 & 5.18 & 5.24 & 5.36 & 5.44 & 5.56 & 5.60 & 5.66 \\
\hline \multirow[t]{2}{*}{ lnSCCPs } & $-.610^{* *}$ & $-.601^{* *}$ & $-.657^{* *}$ & $-.495^{* *}$ & $-.624^{* *}$ & -0.172 & $-.683^{* *}$ & $-.400^{*}$ \\
\hline & 10,8 & 12,7 & 11,8 & 13,6 & 13,5 & 13,7 & 12,8 & 10,9 \\
\hline Log Kow & 5.72 & 5.78 & 5.78 & 5.81 & 5.86 & 5.89 & 5.94 & 6.00 \\
\hline \multirow[t]{2}{*}{$\operatorname{lnSCCPs}$} & $-.433^{*}$ & $.643^{* *}$ & 0.277 & $.574^{* *}$ & 0.058 & $.653^{* *}$ & $.503^{* *}$ & -0.092 \\
\hline & 11,9 & 13,8 & 12,9 & 13,9 & 11,10 & 10,10 & 12,10 & 13,10 \\
\hline Log Kow & 6.02 & 6.04 & 6.11 & 6.22 & 6.25 & 6.27 & 6.29 & 6.42 \\
\hline $\operatorname{lnSCCPs}$ & 0.081 & $.447^{* *}$ & -0.02 & 0.144 & -0.165 & -0.205 & 0.161 & -0.14 \\
\hline
\end{tabular}

**: $\mathrm{p}<0.01 ; *$ : $\mathrm{p}<0.05$.

alkane chain (C10-C18) at given chlorine content, a polynomial effect was observed in dependence on the chlorination degree of an alkane chain. The function of $\log \mathrm{K}_{\mathrm{ow}}$ and chlorine content at an alkane chain, following a polynomial correlation of second order proposed by their study was used to get $\log \mathrm{K}_{\mathrm{ow}}$ value of SCCPs. Pearson correlations were made between SCCP concentrations $\ln$ (SCCPs) and the relative mass abundance of chloroalkanes for a further exploration of the transportation and environmental fate of CPs, shown in Table 2. Strong correlations were found for most individual congener groups with 5-8 chlorine atoms. They were negatively correlated when $\log \mathrm{K}_{\mathrm{ow}}$ values were no higher than 5.72, which means an increasing trend of the relative mass abundance from industrial areas to remote areas. While positive correlations were noticed when $\log \mathrm{K}_{\mathrm{ow}}$ values were higher than 5.78, which means a declination from point sources nearby to faraway places. Congener groups with lower $\log \mathrm{K}_{\mathrm{ow}}$ values are likely to transport to longer places while those with higher $\log \mathrm{K}_{\mathrm{ow}}$ values tend to adsorb/absorb onto particles and sink to sediment. The compositional profiles of MCCPs is coincident with the variation trend of $\log \mathrm{K}_{\mathrm{ow}}$ of MCCPs, which was reported to level off at higher $\mathrm{N}_{\text {tot }}$ (the sum of the number of chlorine and carbon atoms) when it was greater than approximately 20 (Sijm and Sinnige, 1995). But for congener groups with 9 and 10 chlorine atoms, no significant correlations were noticed. There leaves a question open that whether it is due to the leveling off of $\log \mathrm{K}_{\mathrm{ow}}$ values at higher $\mathrm{N}_{\text {tot }}$, or the impact of $\log \mathrm{K}_{\mathrm{ow}}$ values on their transportation had been greatly weakened. To thoroughly figure out this problem, further study as well as method with better sensitivity and accuracy might be needed.

\section{Conclusion}

Spatial trends and transport behaviors in riverine and marine sediments from the Laizhou Bay area were analyzed. Higher levels of $\mathrm{CP}$ contamination were found in sites near industrial areas. The $\mathrm{CP}$ contamination in rivers was mainly associated with emissions from local factories. In the marine sediments of the Laizhou Bay, apart from riverine input, ship related emissions are suggested to be an important source of contaminants. The correlations between relative mass abundance of $\mathrm{CPs}$ and $\mathrm{CP}$ concentrations were examined. A distinct shift to congeners with shorter carbon chains and lower chlorination from emission sources to remote areas as well as from rivers to marine environment was noticed. The role of $\log \mathrm{K}_{\mathrm{ow}}$ values on the transportation was assessed and indicated to be decisive in this area.

\section{Acknowledgements}

The study was funded by the Project supported by the National
Natural Science Foundation of China (Grant No.41103074 and 41773138). Dr. Guo Jie is specially appreciated for her kindly constructing suggestion and providing the ENVISAT ASAR image.

\section{Appendix A. Supplementary data}

Supplementary data to this article can be found online at https://doi.org/10.1016/j.envpol.2018.09.123.

\section{References}

Bettina, H., Hermann, F., Wolfgang, V.l., Mehmet, C., 2011. Effects of chain length, chlorination degree, and structure on the Octanol-Water partition coefficients of polychlorinated n-alkanes. Environ. Sci. Technol. 45, 2842-2849.

Bezchlebová, J., Cernohlávková, J., Kobeticová, K., Lána, J., Sochová, I., Hofman, J., 2007. Effects of short-chain chlorinated paraffins on soil organisms. Ecotoxicol. Environ. Saf. 67, 206-211.

Castells, P., Santos, F.J., Galceran, M.T., 2004. Evaluation of three ionisation modes for the analysis of chlorinated paraffins by gas chromatography/ion-trap mass spectrometry. Rapid Commun. Mass Spectrom. 18, 529-536.

Castells, P., Parera, J., Santos, F.J., Galceran, M.T., 2008. Occurrence of polychlorinated naphthalenes, polychlorinated biphenyls and short-chain chlorinated paraffins in marine sediments from Barcelona (Spain). Chemosphere 70, 1552-1562.

Chen, M.-Y., Luo, X.-J., Zhang, X.-L., He, M.-J., Chen, S.-J., Mai, B.-X., 2011. Chlorinated paraffins in sediments from the Pearl River Delta, south China: spatial and temporal distributions and implication for processes. Environ. Sci. Technol. 45, 9936-9943.

Cherrie, J.W., Semple, S., 2010. Dermal exposure to metalworking fluids and medium-chain chlorinated paraffin (MCCP). Ann. Occup. Hyg. 54, 228-235.

Drouillard, K.G., Hiebert, T., Tran, P., Tomy, G.T., Muir, D.C.G., Friesen, K.J., 1998. Estimating the aqueous solubilities of individual chlorinated n-alkanes (C10-C12) from measurements of chlorinated alkane mixtures. Environ. Toxicol. Chem. 17, 1261-1267.

Feo, M.L., Eljarrat, E., Barceló, D., 2009. Occurrence, fate and analysis of polychlorinated n-alkanes in the environment. Trac. Trends Anal. Chem. 28, 778-791.

Fisk, A.T., Tomy, G.T., Cymbalisty, C.D., Muir, D.C.G., 2000. Dietary accumulation and quantitative structure-activity relationships for depuration and biotransformation of short (C10), medium (C14), and long (C18) carbon-chain polychlorinated alkanes by juvenile rainbow trout (Oncorhynchus mykiss). Environ. Toxicol. Chem. 19, 1508-1516.

Gao, Y., Zhang, H., Su, F., Tian, Y., Chen, J., 2012. Environmental Occurrence and Distribution of Short Chain Chlorinated Paraffins in Sediments and Soils from the Liaohe River Basin. Environmental Science \& Technology, P. R. China.

Gao, Y., Zhang, H., Zou, L., Wu, P., Yu, Z., Lu, X., Chen, J., 2016. Quantification of shortchain chlorinated paraffins by deuterodechlorination combined with gas chromatography-mass spectrometry. Environ. Sci. Technol. 50, 3746-3753.

Geng, N., Zhang, H., Zhang, B., Wu, P., Wang, F., Yu, Z., Chen, J., 2015. Effects of shortchain chlorinated paraffins exposure on the viability and metabolism of human hepatoma HepG2 cells. Environ. Sci. Technol. 49, 3076-3083.

Hilger, B., Fromme, H., Völkel, W., Coelhan, M., 2013. Occurrence of chlorinated paraffins in house dust samples from Bavaria, Germany. Environ. Pollut. 175, $16-21$.

Huttig, J., Oehme, M., 2005. Presence of chlorinated paraffins in sediments from the North and baltic seas. Arch. Environ. Contam. Toxicol. 49, 449-456.

Huttig, J., Oehme, M., 2006. Congener group patterns of chloroparaffins in marine sediments obtained by chloride attachment chemical ionization and electron capture negative ionization. Chemosphere 64, 1573-1581.

Iino, F., Takasuga, T., Senthilkumar, K., Nakamura, N., Nakanishi, J., 2005. Risk assessment of short-chain chlorinated paraffins in Japan based on the first market basket study and species sensitivity distributions. Environ. Sci. Technol. 
39, 859-866.

Iozza, S., Müller, C.E., Schmid, P., Bogdal, C., Oehme, M., 2008. Historical profiles of chlorinated paraffins and polychlorinated biphenyls in a dated sediment core from lake thun (Switzerland). Environ. Sci. Technol. 42, 1045-1050.

Iozza, S., Schmid, P., Oehme, M., 2009. Development of a comprehensive analytical method for the determination of chlorinated paraffins in spruce needles applied in passive air sampling. Environ. Pollut. 157, 3218-3224.

Ismail, N., Gewurtz, S.B., Pleskach, K., Whittle, D.M., Helm, P.A., Marvin, C.H., Tomy, G.T., 2009. Brominated and chlorinated flame retardants in lake Ontario, Canada, lake trout (Salvelinus Namaycush) between 1979 and 2004 and possible influences of food-web changes. Environ. Toxicol. Chem. 28, 910-920.

Jiang, W., Huang, T., Mao, X., Wang, L., Zhao, Y., Jia, C., Wang, Y., Gao, H., Ma, J., 2017. Gridded emission inventory of short-chain chlorinated paraffins and its validation in China. Environ. Pollut. 220, 132-141.

Ma, X., Chen, C., Zhang, H., Gao, Y., Wang, Z., Yao, Z., Chen, J., Chen, J., 2014a. Congener-specific distribution and bioaccumulation of short-chain chlorinated paraffins in sediments and bivalves of the Bohai Sea, China. Mar. Pollut. Bull. 79, 299-304.

Ma, X., Zhang, H., Wang, Z., Yao, Z., Chen, J., Chen, J., 2014b. Bioaccumulation and trophic transfer of short chain chlorinated paraffins in a marine food web from Liaodong bay, North China. Environ. Sci. Technol. 48, 5964-5971.

Mackay, D., Shiu, W.Y., Ma, K.C., 1993. Illustrated Handbook of Physical-chemical Properties and Environmental Fate for Organic Chemicals. III. Volatile Organic Chemicals. Lewis Publishers, Inc., Boca Raton, USA.

Pan, X., Tang, J., Chen, Y., Li, J., Zhang, G., 2011a. Polychlorinated naphthalenes (PCNs) in riverine and marine sediments of the Laizhou Bay area, North China. Environ. Pollut. 159, 3515-3521.

Pan, X., Tang, J., Li, J., Zhong, G., Chen, Y., Zhang, G., 2011b. Polybrominated diphenyl ethers (PBDEs) in the riverine and marine sediments of the Laizhou Bay area, North China. J. Environ. Monit. 13, 886-893.

Pribylová, P., Klánová, J., Holoubek, I., 2006. Screening of short- and medium-chain chlorinated paraffins in selected riverine sediments and sludge from the Czech Republic. Environ. Pollut. 144, 248-254.

Reth, M., Oehme, M., 2004. Limitations of low resolution mass spectrometry in the electron capture negative ionization mode for the analysis of short- and medium-chain chlorinated paraffins. Anal. Bioanal. Chem. 378, 1741-1747.

Reth, M., Zencak, Z., Oehme, M., 2017. New quantification procedure for the analysis of chlorinated paraffins using electron capture negative ionization mass spectrometry. J. Chromatogr. A 1081, 225-231.

Sijm, D.T.H.M., Sinnige, T.L., 1995. Experimental octanol/water partition coefficients of chlorinated paraffins. Chemosphere 31, 4427-4435.

Stejnarová, P., Coelhan, M., Kostrhounová, R., Parlar, H., Holoubek, I., 2005. Analysis of short chain chlorinated paraffins in sediment samples from the Czech Republic by short-column GC/ECNI-MS. Chemosphere 58, 253-262.

Tomy, G.T., Stern, G.A., Muir, D.C.G., Fisk, A.T., Cymbalisty, C.D., Westmore, J.B., 1997. Quantifying C10-C13 polychloroalkanes in environmental samples by highresolution gas chromatography/electron capture negative ion high-resolution mass spectrometry. Anal. Chem. 69, 2762-2771.

Tomy, G.T., Stern, G.A., Lockhart, W.L., Muir, D.C.G., 1999. Occurrence of C10-C13 polychlorinated n-alkanes in canadian midlatitude and arctic lake sediments, Environ. Sci. Technol. 33, 2858-2863.
UNEP/POPS/POPRC.12/11/Add3, 2017. Report of the Persistent Organic Pollutants Review Committee on the Work of its Twelfth Meeting: Risk Management Evaluation on Short-chain Chlorinated Paraffins.

Wang, Y., Gao, W., Jiang, G., 2017. Strengthening the study on the behavior and transformation of medium-chain chlorinated paraffins in the environment. Environ. Sci. Technol. 51, 10282-10283.

Warnasuriya, G.D., Foster, J.R., Elcombe, B.M., Elcombe, C.R., 2000. Mechanism of carcinogenicity of a short chain chlorinated paraffin, Chlorowax 500C, in male fischer 344 rats in comparison to 1,4-dichlorobenzene and d-limonene. Toxicology 148, 63-63.

Wei, G.-L., Liang, X.-L., Li, D.-Q., Zhuo, M.-N., Zhang, S.-Y., Huang, Q.-X., Liao, Y.-S., Xie, Z.-Y., Guo, T.-L., Yuan, Z.-J., 2016. Occurrence, fate and ecological risk of chlorinated paraffins in Asia: a review. Environ. Int. 92-93, 373-387.

Yuan, B., Brüchert, V., Sobek, A., de Wit, C.A., 2017. Temporal trends of C8-C36 chlorinated paraffins in Swedish coastal sediment cores over the past 80 years. Environ. Sci. Technol. 51, 14199-14208.

Zeng, L., Wang, T., Han, W., Yuan, B., Liu, Q., Wang, Y., Jiang, G., 2011a. Spatial and vertical distribution of short chain chlorinated paraffins in soils from wastewater irrigated farmlands. Environ. Sci. Technol. 45, 2100-2106.

Zeng, L., Wang, T., Wang, P., Liu, Q., Han, S., Yuan, B., Zhu, N., Wang, Y., Jiang, G., 2011b. Distribution and trophic transfer of short-chain chlorinated paraffins in an aquatic ecosystem receiving effluents from a sewage treatment plant. Environ. Sci. Technol. 45, 5529-5535.

Zeng, L., Zhao, Z., Li, H., Thanh, W., Liu, Q., Xiao, K., Du, Y., Wang, Y., Jiang, G., 2012. Distribution of short chain chlorinated paraffins in marine sediments of the east China sea: influencing factors, transport and implications. Environ. Sci. Technol. 46, 9898-9906.

Zeng, L., Chen, R., Zhao, Z., Wang, T., Gao, Y., Li, A., Wang, Y., Jiang, G., Sun, L., 2013. Spatial distributions and deposition chronology of short chain chlorinated paraffins in marine sediments across the Chinese Bohai and Yellow seas. Environ. Sci. Technol. 47, 11449-11456.

Zeng, L., Lam, J.C.W., Horii, Y., Li, X., Chen, W., Qiu, J.-W., Leung, K.M.Y., Yamazaki, E., Yamashita, N., Lam, P.K.S., 2017. Spatial and temporal trends of short- and medium-chain chlorinated paraffins in sediments off the urbanized coastal zones in China and Japan: a comparison study. Environ. Pollut. 224, 357-367.

Zhang, R., Zhang, G., Zheng, Q., Tang, J., Chen, Y., Xu, W., Zou, Y., Chen, X., Occurrence and risks of antibiotics in the Laizhou Bay, China: impacts of river discharge. Ecotoxicol. Environ. Saf..

Zhang, B., Zhao, B., Xu, C., Zhang, J., 2017. Emission inventory and provincial distribution of short-chain chlorinated paraffins in China. Sci. Total Environ. $581-582,582-588$.

Zhao, Z., Li, H., Wang, Y., Li, G., Cao, Y., Zeng, L., Lan, J., Wang, T., Jiang, G., 2013a. Source and migration of short-chain chlorinated paraffins in the coastal east China sea using multiproxies of marine organic geochemistry. Environ. Sci. Technol. 47, 5013-5022.

Zhao, Z., Tang, J., Xie, Z., Chen, Y., Pan, X., Zhong, G., Sturm, R., Zhang, G., Ebinghaus, R., 2013b. Perfluoroalkyl acids (PFAAs) in riverine and coastal sediments of Laizhou Bay, North China. Sci. Total Environ. 447, 415-423.

Zhong, G., Tang, J., Zhao, Z., Pan, X., Chen, Y., Li, J., Zhang, G., 2011. Organochlorine pesticides in sediments of Laizhou Bay and its adjacent rivers, North China. Mar. Pollut. Bull. 62, 2543-2547. 